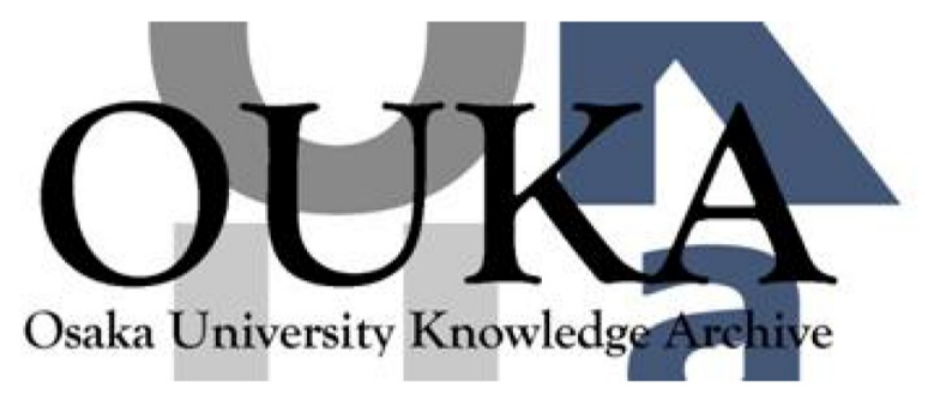

\begin{tabular}{|c|l|}
\hline Title & $\begin{array}{l}\text { Solvent-Dependent Conformation of Amy lose } \\
\text { Tris(Phenylcarbamate) as Deduced from } \\
\text { Scattering and Viscosity Data }\end{array}$ \\
\hline Author(s) & Fujii, Taichi; Terao, Ken; Tsuda, Maiko et al. \\
\hline Citation & Biopolymers. 91(9) p. 729-p. 736 \\
\hline Issue Date & $2009-04$ \\
\hline oaire:version & AM \\
\hline URL & https://hdl. handle. net/11094/53323 \\
\hline rights & \\
\hline Note & \\
\hline
\end{tabular}

Osaka University Knowledge Archive : OUKA

https://ir. Library. osaka-u. ac. jp/

Osaka University 


\title{
Solvent-Dependent Conformation of Amylose Tris(Phenylcarbamate) as Deduced from Scattering and Viscosity Data
}

\author{
Taichi Fujii,, ${ }^{1}$ Ken Terao, ${ }^{1}$ Maiko Tsuda, ${ }^{1}$ Shinichi Kitamura, ${ }^{2}$ Takashi Norisuye ${ }^{1}$ \\ ${ }^{1}$ Department of Macromolecular Science, Osaka University, 1-1, Machikaneyama-cho, Toyonaka, \\ Osaka, 560-0043, Japan \\ ${ }^{2}$ Graduate School of Life and Environmental Sciences, Osaka Prefecture University, Gakuen-cho, \\ Nakaku, Sakai, Osaka 599-8531, Japan
}

Running Head: Amylose Tris(Phenylcarbamate) in Solution

Correspondence to K. Terao: (E-mail:kterao@chem.sci.osaka-u.ac.jp)

\begin{abstract}
The $z$-average mean-square radius of gyration $\left\langle S^{2}\right\rangle_{z}$, the particle scattering function $P(k)$, the second virial coefficient, and the intrinsic viscosity $[\eta]$ have been determined for amylose tris(phenylcarbamate) (ATPC) in methyl acetate (MEA) at $25^{\circ} \mathrm{C}$, in ethyl acetate (EA) at $33^{\circ} \mathrm{C}$, and in 4-methyl-2-pentanone (MIBK) at $25^{\circ} \mathrm{C}$ by light and small-angle X-ray scattering and viscometry as functions of the weight-average molecular weight in a range from $2 \times 10^{4}$ to $3 \times 10^{6}$. The first two solvents attain the theta state, while the last one is a good solvent for the amylose derivative. Analysis of the $\left\langle S^{2}\right\rangle_{z}, P(k)$, and $[\eta]$ data based on the wormlike chain yields $h$ (the contour length or helix pitch per repeating unit) $=0.37 \pm 0.02$ and $\lambda^{-1}$ (the Kuhn segment length) $=15 \pm 2 \mathrm{~nm}$ in MEA, $h=0.39 \pm 0.02$ and $\lambda^{-1}=17 \pm 2 \mathrm{~nm}$ in EA, and $h=0.42 \pm 0.02 \mathrm{~nm}$ and $\lambda^{-1}=24 \pm 2 \mathrm{~nm}$ in MIBK . These $h$ values, comparable to the helix pitches $(0.37-0.40 \mathrm{~nm})$ per residue of amylose triesters in the crystalline state, are somewhat larger than the previously determined $h$ of $0.33 \pm 0.02 \mathrm{~nm}$ for ATPC in 1,4-dioxane and 2-ethoxyethanol, in which intramolecular hydrogen bonds are formed between the $\mathrm{C}=\mathrm{O}$ and $\mathrm{NH}$ groups of the neighbor repeating units. The slightly extended helices of ATPC in the ketone and ester solvents are most likely due to the replacement of those hydrogen bonds by intermolecular hydrogen bonds between the NH groups of the polymer and the carbonyl groups of the solvent.
\end{abstract}

Keywords: amylose; wormlike chain; light scattering; SAXS; viscosity 


\section{INTRODUCTION}

Amylose tris(phenylcarbamate) (ATPC), whose chemical structure is shown in Chart 1, behaves as a semiflexible chain ${ }^{1-7}$ with locally helical structure ${ }^{8,9}$ in dilute solution. Its stiffness expressed in terms of the Kuhn segment length $\lambda^{-1}$ (about $20 \mathrm{~nm}$ ) in the wormlike chain model ${ }^{10}$ or more generally the stiffness parameter in the helical wormlike chain ${ }^{11}$ is much higher than that of amylose $(4 \mathrm{~nm}) .{ }^{12,13}$ Very recently, ${ }^{9}$ we analyzed the scattering function and viscosity data for the amylose derivative based on the wormlike chain model, and found that the helix pitch $h$ per residue or the contour length per residue of ATPC is $0.33 \pm 0.02 \mathrm{~nm}$ in 1,4-dioxane (DIOX) and 2-ethoxyethanol (2EE), i.e., a value appreciably smaller than what is known for the helices of amylose triesters $(0.37$ $-0.40 \mathrm{~nm}$ ) in the crystalline state. ${ }^{14,15}$ We explained this shorter pitch as due to the intramolecular hydrogen bonding between $\mathrm{C}=\mathrm{O}$ and $\mathrm{NH}$ groups of neighbor repeating units of ATPC on the basis of the observed IR (infrared absorption) spectra in the two solvents.

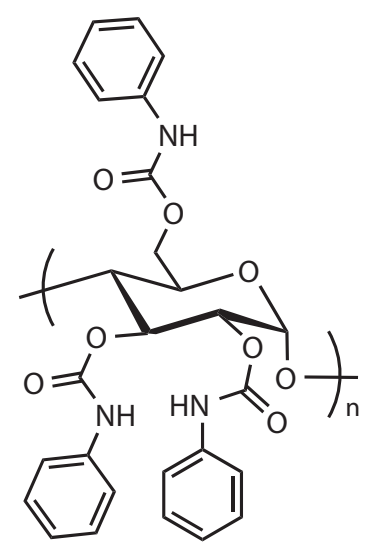

CHART 1 Chemical structure of amylose tris(phenylcarbamate) ATPC.

The above work prompted us to see whether the shorter helix pitch is characteristic of ATPC in solution or extends to a value comparable to $0.37-0.40 \mathrm{~nm}$ for the crystalline amylose triesters when the solvent conditions are changed. Except for our data in DIOX and 2EE, virtually no information on $h$ was available for this polymer in the literature. In this situation, we deemed it legitimate to use as solvents ketones or esters whose $\mathrm{C}=\mathrm{O}$ groups are capable of strongly interacting with the NH groups of ATPC, even though such solvents did not always allow IR spectroscopy in a relevant range of wavelength.

The present study was undertaken to determine $h$ and $\lambda^{-1}$ for ATPC in methyl acetate (MEA), ethyl acetate (EA), and 4-methyl-2-pentanone (MIBK) by light and small-angle X-ray scattering (SAXS) and viscometry. The two ester solvents were found to attain the theta state (see the Experimental section). We also found that, as shown in Figure 1, the intrinsic viscosity $[\eta]$ of an ATPC sample $(\mathrm{ATPC} 3 \mathrm{M})^{9}$ with a weight-average molecular weight $M_{\mathrm{w}}$ of $3.27 \times 10^{6}$ (at $25^{\circ} \mathrm{C}$ ) depends significantly on the molar volume $v_{\mathrm{M}}$ of the solvent while that of cellulose tris(phenylcarbamate) (CTPC) sample ${ }^{16}$ with a comparable $M_{\mathrm{w}}$ of $2.62 \times 10^{6}$ has no such tendency. This suggests that 
the dimensions of the ATPC molecule and hence the degree of chain extension have something to do with the bulkiness around the carbonyl groups of the solvent molecules. Since the chain extension (in the unperturbed state) arises from an increase in either $h$ or $\lambda^{-1}$ or increases in both, separate estimation of the two molecular parameters and comparison with those in DIOX and 2EE should serve to clarify solvent effects on the conformation of ATPC.

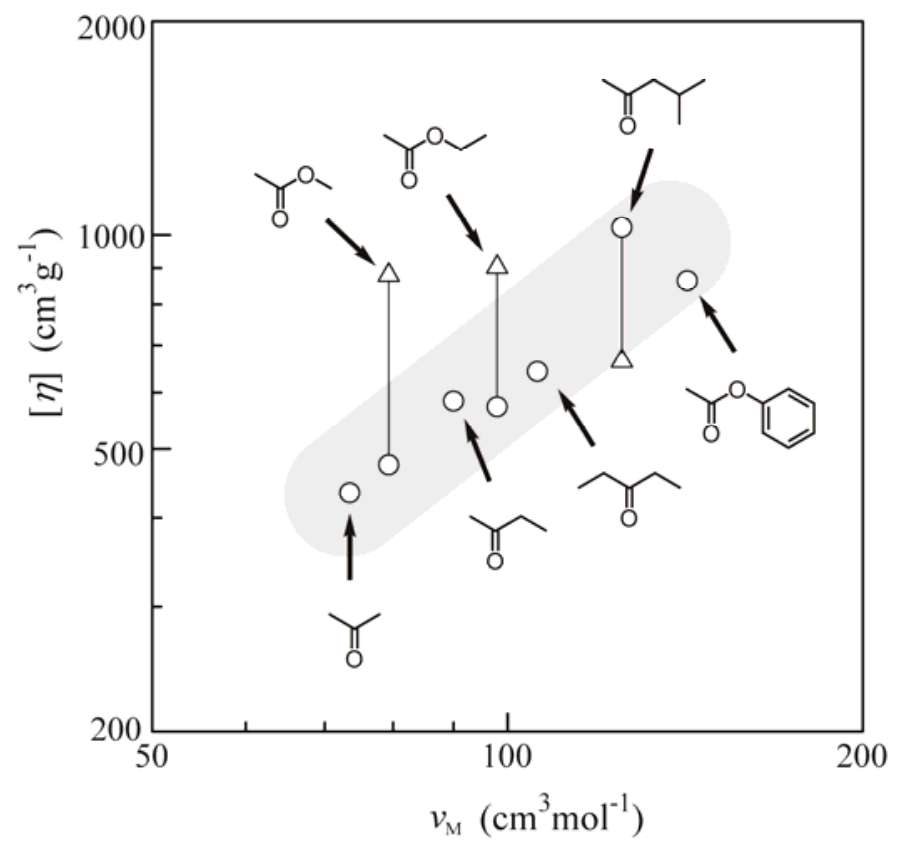

FIGURE 1 Dependence of $[\eta]$ on the molar volume of solvent for ATPC3M (circles) and a CTPC sample with $M_{\mathrm{w}}=2.62 \times 10^{6}$ (triangles) at $25^{\circ} \mathrm{C}$.

\section{EXPERIMENTAL}

\section{Samples}

Seven previously investigated ATPC samples ${ }^{9}$ (ATPC3M, ATPC800K, ATPC500K, ATPC300K, ATPC200K, ATPC50K, and ATPC20K) ranging in $M_{\mathrm{w}}$ from $2 \times 10^{4}$ to $3 \times 10^{6}$ were used for the present study. These samples with the full degree of substitution had been prepared from enzymatically synthesized amylose ${ }^{17}$ and phenylisocyanate. The ratios of $M_{\mathrm{w}}$ to the number-average molecular weight or those of the z-average molecular weight to $M_{\mathrm{w}}$ were in the range between 1.05 and 1.11. ${ }^{9} \quad$ MEA, EA, and MIBK were purified by fractional distillation over $\mathrm{CaH}_{2}$.

\section{Light Scattering}

Intensities of light scattered from ATPC solutions were measured for five higher molecular weight samples in EA, MEA, and MIBK on a Fica-50 light scattering photometer at a wavelength $\lambda_{0}$ of 436 $\mathrm{nm}$; sample ATPC $800 \mathrm{~K}$ could not be studied in EA and MIBK because of its poor solubility in the two solvents. The procedures including the calibration of the photometer were the same as those 
described previously. ${ }^{9} \quad$ The square-root plot $^{18}$ was used to evaluate $M_{\mathrm{w}}$, the particle scattering function $P(k)$ ( $k$ denotes the magnitude of the scattering vector), the $z$-average mean-square radius of gyration $\left\langle S^{2}>_{z}\right.$, and the second virial coefficient $A_{2}$. The specific refractive index increments $\partial n / \partial c$ at $\lambda_{0}=436,546$, and $633 \mathrm{~nm}$ were determined for sample ATPC $800 \mathrm{~K}$ in MEA at 20,30 , and $40{ }^{\circ} \mathrm{C}$, for ATPC3M in EA at 10,20 , and $25^{\circ} \mathrm{C}$, and for ATPC $3 \mathrm{M}$ in MIBK at $25^{\circ} \mathrm{C}$ (see Supplementary Material for the numerical data).

In our preliminary intensity measurements, the temperature $T$ was varied in the range between 25 and $50{ }^{\circ} \mathrm{C}$ in expectation of the presence of the theta condition near room temperature, because ATPC solutions of the three solvents became clouded at elevated temperatures, indicating that they have lower critical solution temperatures (LCST). Figure 2 shows that $A_{2}$ for ATPC vanishes in EA at $33{ }^{\circ} \mathrm{C}$ and in MEA (within experimental errors) at any $T$ between 25 and $40{ }^{\circ} \mathrm{C}$. Thus, these temperatures can be regarded as the theta points for the polymer in the respective solvents. For MEA solutions, we chose scattering data at $25^{\circ} \mathrm{C}$ (the lowest $T$ ) as those at the theta temperature; the solutions were less stable at $45^{\circ} \mathrm{C}$ and higher temperatures (due to pronounced scattering-intensity fluctuation). The $A_{2}$ values of about $1.8 \times 10^{-4} \mathrm{~mol} \mathrm{~cm}^{3} \mathrm{~g}^{-2}$ in MIBK, shown by the half-filled symbols in the figure, are comparable to those in DIOX, indicating that, as is the case with DIOX, MIBK at $25^{\circ} \mathrm{C}$ is a good solvent for ATPC.

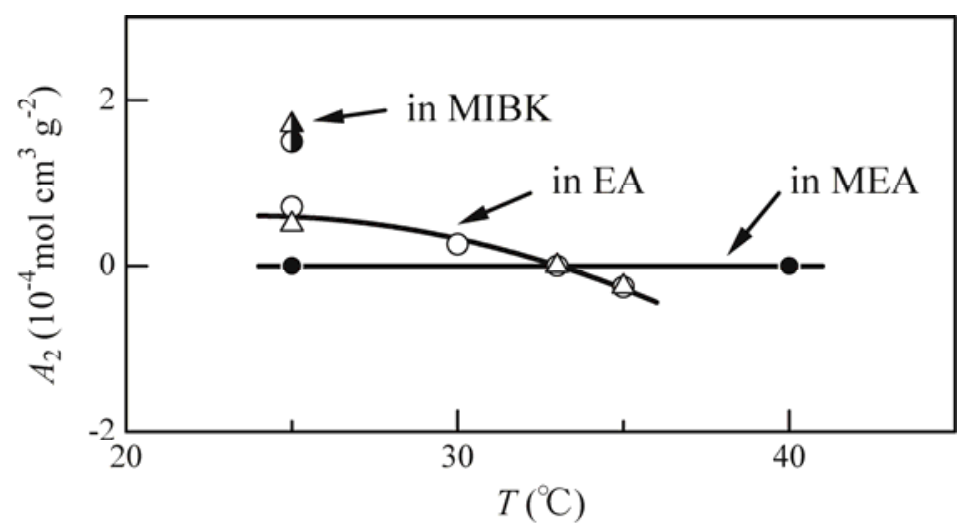

FIGURE 2 Temperature dependence of $A_{2}$ for samples ATPC3M (circles) and ATPC500K (triangles) in MEA (filled symbols), in EA (unfilled symbols), and in MIBK (half-filled symbols).

\section{Small-Angle X-Ray Scattering}

SAXS measurements were made on two samples ATPC50K and ATPC20K in MEA at $25^{\circ} \mathrm{C}$, in EA at $33{ }^{\circ} \mathrm{C}$, and in MIBK at $25^{\circ} \mathrm{C}$ with an imaging plate detector at the BL40B2 beamline in SPring- 8 . The camera length and $\lambda_{0}$ were set to be $1500 \mathrm{~mm}$ and $0.1 \mathrm{~nm}$, respectively (see ref 9 for other experimental details). Four solutions of different polymer mass concentrations $c$ were studied for each combination of sample and solvent, and intensity data were extrapolated to infinite dilution using the square-root plot $^{18}$ to determine $\left\langle S^{2}>_{\mathrm{z}}\right.$ and $P(k)$. 


\section{Viscometry}

Intrinsic viscosities at zero shear rate were determined for ATPC samples in the three solvents at the same temperatures as those in the SAXS experiment using a four-bulb low-shear capillary viscometer and conventional capillary viscometers of the Ubbelohde type; shear-rate effects on $[\eta]$ were appreciable $(2 \%)$ only for the highest molecular weight sample ATPC3M in MIBK. Huggins' constants were in a range between 0.34 and 0.82 , but those for ATPC20K (the lowest $M_{\mathrm{w}}$ sample) in MEA and MIBK slightly exceeded unity.

\section{RESULTS}

Figure 3 illustrates plots of $\left(K c / R_{0}\right)^{1 / 2}$ vs $c$ for ATPC samples in MEA at $25{ }^{\circ} \mathrm{C}$, EA at $33{ }^{\circ} \mathrm{C}$, and MIBK at $25{ }^{\circ} \mathrm{C}$, where $K$ and $R_{0}$ denote the optical constant and the reduced scattering intensity at zero scattering angle, respectively. While the indicated lines in panel (c) have positive slopes as expected for a good solvent, those in panels (a) and (b) are almost horizontal, confirming that MEA at $25{ }^{\circ} \mathrm{C}$ and EA at $33{ }^{\circ} \mathrm{C}$ are theta solvents for ATPC. The values of $M_{\mathrm{w}}$ evaluated from the intercepts for each sample in the three solvents agreed with our previous $M_{\mathrm{w}}$ in DIOX and 2EE within $\pm 6 \%$. Thus, the averages of $M_{\mathrm{w}}$ 's from these five solvents are presented in Table 1 . The angular dependence of $P(k)^{-1 / 2}$ is depicted for the seven samples in the three solvents in Figure 4. The values of $\left\langle S^{2}\right\rangle_{z}$ evaluated from the initial slopes (the dashed lines) are summarized in Table 1, along with those of $[\eta]$.

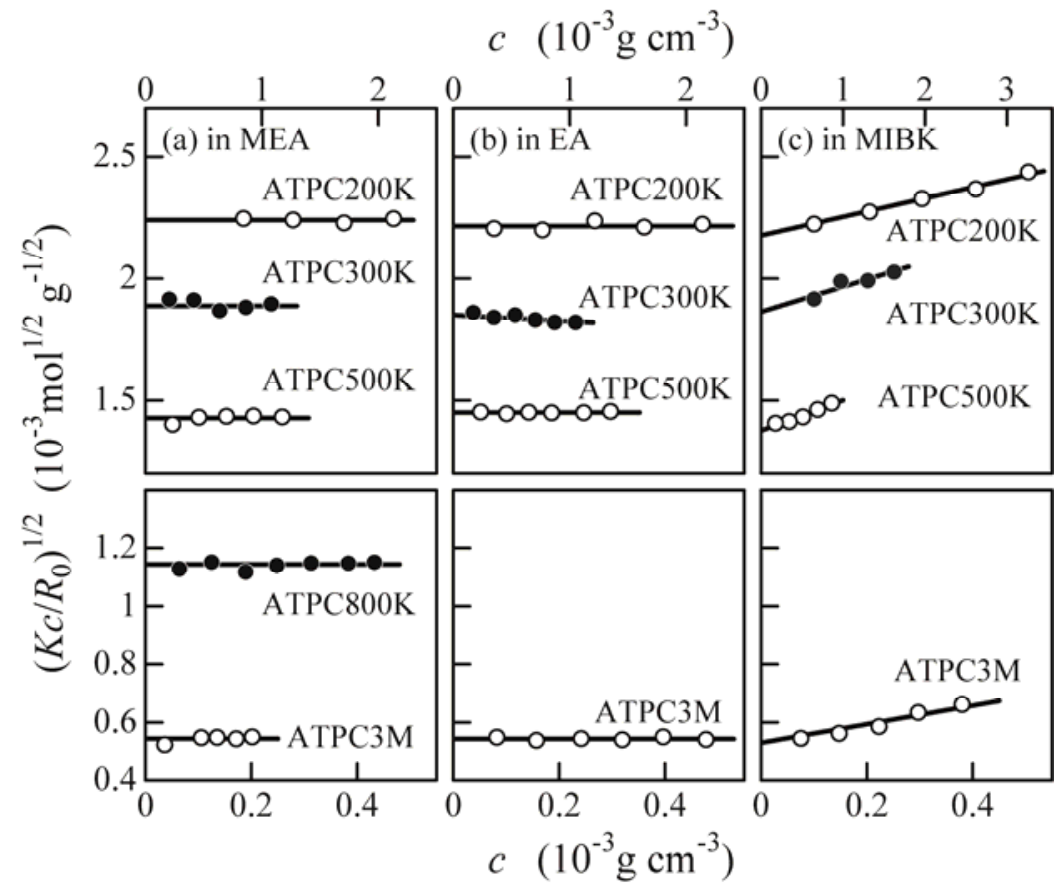

FIGURE 3 Concentration dependence of $\left(K c / R_{0}\right)^{1 / 2}$ for indicated ATPC samples in MEA at 25 ${ }^{\circ} \mathrm{C}(\mathrm{a})$, in EA at $33^{\circ} \mathrm{C}(\mathrm{b})$, and in MIBK at $25^{\circ} \mathrm{C}(\mathrm{c})$. 
Table 1. Numerical Results from Light Scattering, SAXS, and Viscosity Measurements on ATPC Samples in Methyl Acetate (MEA) at $25^{\circ} \mathrm{C}$, Ethyl Acetate (EA) at $33^{\circ} \mathrm{C}$, and 4-Methyl-2-pentanone (MIBK) at $25^{\circ} \mathrm{C}$

\begin{tabular}{|c|c|c|c|c|c|c|c|}
\hline \multirow{2}{*}{ Sample } & \multirow{2}{*}{$\frac{M_{\mathrm{w}}}{10^{4}}$} & \multicolumn{2}{|c|}{ in MEA } & \multicolumn{2}{|c|}{ in $\mathrm{EA}$} & \multicolumn{2}{|c|}{ in MIBK } \\
\hline & & $\begin{array}{c}<S^{2}>_{\mathrm{z}} 1 / 2 \\
(\mathrm{~nm})\end{array}$ & $\begin{array}{c}{[\eta]} \\
\left(\mathrm{cm}^{3} \mathrm{~g}^{-1}\right)\end{array}$ & $\begin{array}{c}<S^{2}>_{\mathrm{z}} 1 / 2 \\
(\mathrm{~nm})\end{array}$ & $\begin{array}{c}{[\eta]} \\
\left(\mathrm{cm}^{3} \mathrm{~g}^{-1}\right)\end{array}$ & $\begin{array}{c}<S>_{\mathrm{z}} 1 / 2 \\
(\mathrm{~nm})\end{array}$ & $\begin{array}{c}{[\eta]} \\
\left(\mathrm{cm}^{3} \mathrm{~g}^{-1}\right)\end{array}$ \\
\hline ATPC3M & $333^{c}$ & $80^{a}$ & 475 & $91^{\text {a }}$ & 495 & 107 a & 1030 \\
\hline ATPC800K & $76.5^{\mathrm{c}}$ & $36.1^{\text {a }}$ & 151 & & & & \\
\hline ATPC500K & $49.1^{\mathrm{c}}$ & $30.8^{a}$ & 126 & 32.9 a & 156 & $39.6^{\text {a }}$ & 226 \\
\hline ATPC $300 \mathrm{~K}$ & $28.2^{c}$ & 22.9 a & 88.7 & $25.5^{\text {a }}$ & 110 & $30.8^{a}$ & 157 \\
\hline ATPC200K & $19.9 \mathrm{c}$ & $18.8^{\text {a }}$ & 62.5 & $21.3^{\mathrm{a}}$ & 67.7 & $24.1^{\mathrm{a}}$ & 88.8 \\
\hline ATPC50K & $5.48^{\mathrm{d}}$ & $7.6 \mathrm{~b}$ & 24.0 & $8.6^{b}$ & 27.7 & $10.3 \mathrm{~b}$ & 30.9 \\
\hline ATPC20K & $1.87 \mathrm{~d}$ & $3.5^{b}$ & 8.7 & $3.8^{b}$ & 9.8 & $4.0^{\mathrm{b}}$ & 10.6 \\
\hline
\end{tabular}

${ }^{\mathrm{a}}$ Light scattering. ${ }^{\mathrm{b}}$ SAXS. ${ }^{\mathrm{c}}$ Average of $M_{\mathrm{w}}$ 's determined from light scattering in different solvents (see text). ${ }^{\mathrm{d}}$ Ref. 9

Figure 5(a) illustrates the molecular weight dependence of $<S^{2}>_{\mathrm{Z}} / M_{\mathrm{w}}$ in MEA at $25{ }^{\circ} \mathrm{C}$, EA at 33 ${ }^{\circ} \mathrm{C}$, and MIBK at $25^{\circ} \mathrm{C}$ along with our previous data. ${ }^{9} \quad$ As $M_{\mathrm{w}}$ increases, $<S^{2}>_{\mathrm{z}} / M_{\mathrm{w}}$ in any solvent rises and then almost levels off at a constant. This behavior is typical of the unperturbed wormlike chain, ${ }^{19}$ and, as was previously found to be the case in DIOX and 2EE, excluded-volume effects on $\left\langle S^{2}>_{\mathrm{z}}\right.$ in MIBK must be small, if any. Although the values of $\left\langle S^{2}>_{\mathrm{Z}} / M_{\mathrm{w}}\right.$ for low molecular weight samples in MEA, EA, and MIBK are different from one another, they are slightly larger than those in DIOX and 2EE. This suggests that $h$ should be somewhat larger in the former group of solvents than in the latter group, since $\left\langle S^{2}>_{\mathrm{z}}\right.$ at low $M_{\mathrm{w}}$ is sensitive not to the chain stiffness but to $h$.

The molecular weight dependence of $[\eta] / M_{\mathrm{w}}{ }^{1 / 2}$ is shown in Figure $5(\mathrm{~b}) . \quad$ Interestingly, $[\eta] / M_{\mathrm{w}}{ }^{1 / 2}$ at low $M_{\mathrm{w}}$ is almost independent of the kind of solvent, differing from the solvent-dependent $<S^{2}>_{\mathrm{Z}} / M_{\mathrm{W}}$ observed above. This seemingly contrasted finding may be reconciled if an ATPC chain with a larger $h$ (i.e., a more extended helix) has a thinner diameter. 


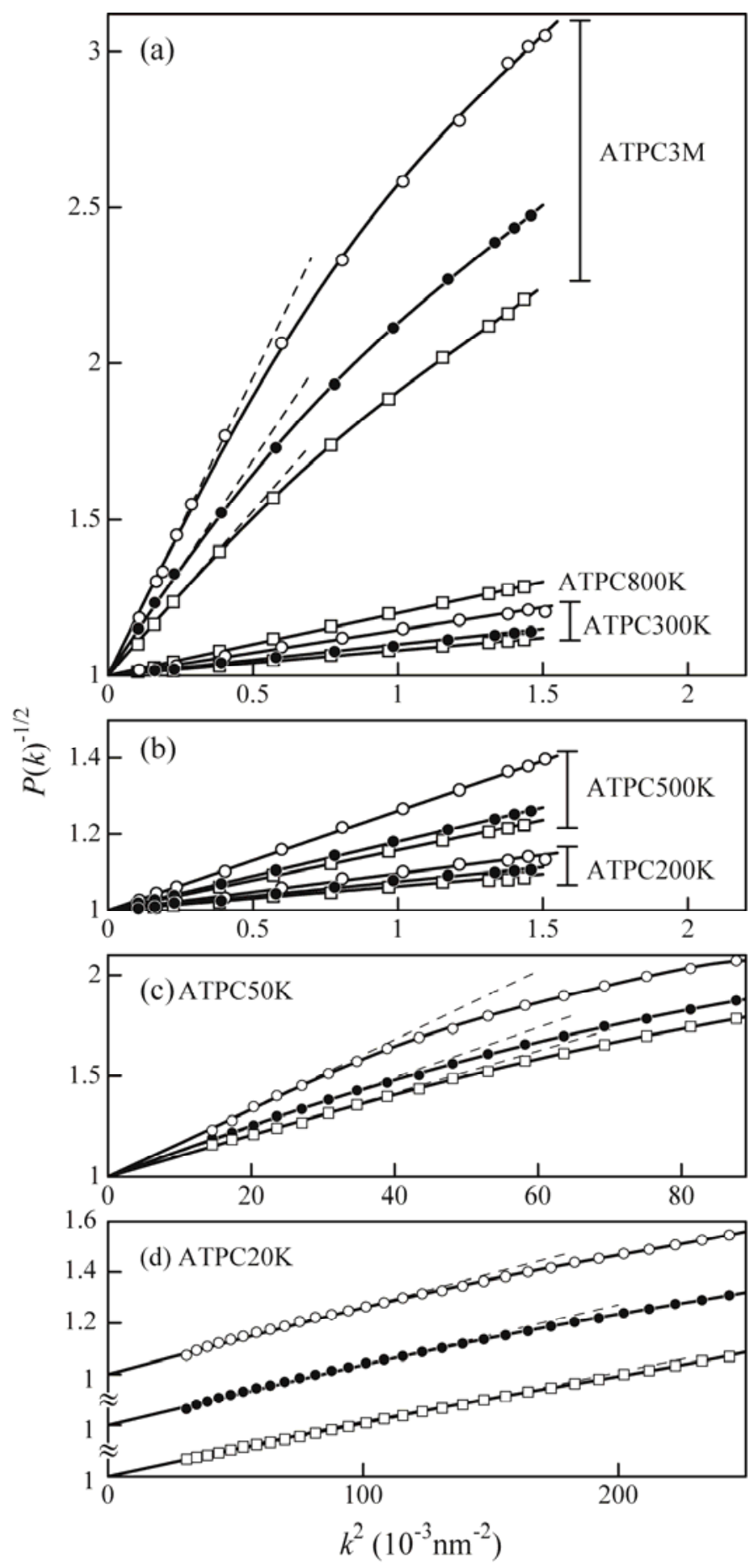

FIGURE 4 Angular dependence of $P(k)^{-1 / 2}$ for ATPC samples in MEA at $25^{\circ} \mathrm{C}$ (squares), in EA at $33{ }^{\circ} \mathrm{C}$ (filled circles), and in MIBK at $25^{\circ} \mathrm{C}$ (unfilled circles). 


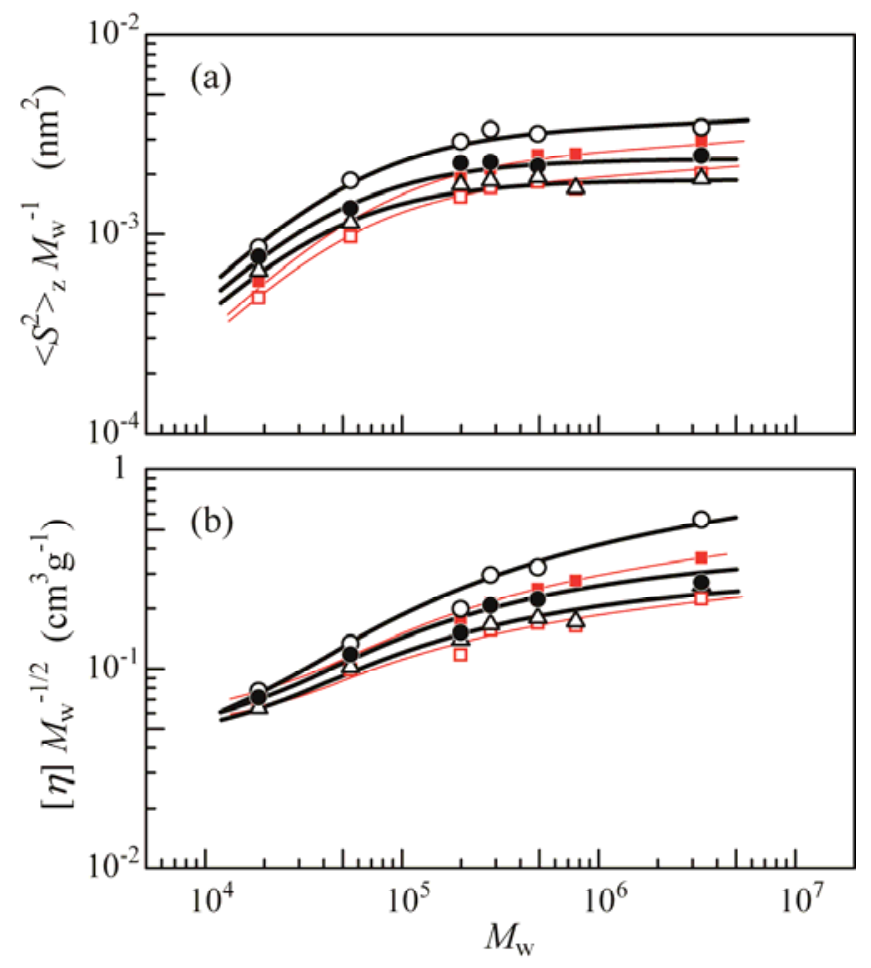

FIGURE 5 Molecular weight dependence of (a) $<S^{2}>_{\mathrm{z}} M_{\mathrm{w}}{ }^{-1}$ and (b) $[\eta] M_{\mathrm{w}}{ }^{-1 / 2}$ for ATPC in MEA at $25{ }^{\circ} \mathrm{C}$ (triangles), in EA at $33{ }^{\circ} \mathrm{C}$ (filled circles), and in MIBK at $25{ }^{\circ} \mathrm{C}$ (unfilled circles), compared with previous data ${ }^{9}$ in DIOX at $25^{\circ} \mathrm{C}$ (filled squares) and in $2 \mathrm{EE}$ at $25^{\circ} \mathrm{C}$ (unfilled squares).

\section{DISCUSSION}

\section{Data analysis in terms of the wormlike chain model - Radius of Gyration}

We analyze the present $\left\langle S^{2}>_{z}\right.$ data in MEA, EA, and MIBK in terms of the wormlike chain whose unperturbed mean-square radius of gyration $\left\langle S^{2}\right\rangle_{0}$ is given by ${ }^{19}$

$$
\left\langle S^{2}\right\rangle_{0}=\frac{L}{6 \lambda}-\frac{1}{4 \lambda^{2}}+\frac{1}{4 \lambda^{3} L}-\frac{1}{8 \lambda^{4} L^{2}}[1-\exp (-2 \lambda L)]
$$

Here, $L$ is the contour length related to the molar mass $M$ of the chain by

$$
L=M / M_{\mathrm{L}}
$$

with $M_{\mathrm{L}}$ the molar mass per unit contour length. The two parameters, $M_{\mathrm{L}}$ and $\lambda^{-1}$, were determined by curve fitting, but for MIBK solutions, correction was made for excluded-volume effect using the Domb-Barrett equation ${ }^{20}$ for the radius expansion factor $\alpha_{\mathrm{s}}$ in the Yamakawa-Stockmayer-Shimada scheme, i.e., the quasi-two-parameter (QTP) theory, ${ }^{11,21,22}$ in 
which $\alpha_{\mathrm{s}}$ is a universal function of the scaled excluded-volume parameter determined by $L, \lambda^{-1}$, and the excluded-volume strength $B$.

The estimated wormlike-chain parameters in the three solvents are summarized in Table 2, and the theoretical solid lines are compared with the experimental data in Figure 6, in which the dashed line drawn for MIBK refers to the unperturbed state. The fits of the solid curves are satisfactory. It should be noted that the excluded-volume effects on $\left\langle S^{2}>_{z}^{1 / 2}\right.$ in MIBK are quite small (less than $4 \%$ ) even for the highest $M_{\mathrm{w}}$ sample studied.

Table 2. Wormlike Chain Parameters for ATPC

ATPC in MEA at $25^{\circ} \mathrm{C}$

\begin{tabular}{llll} 
Method & $M_{\mathrm{L}}\left(\mathrm{nm}^{-1}\right)$ & $\lambda^{-1}(\mathrm{~nm})$ & $d(\mathrm{~nm})$ \\
\hline$<S^{2}>_{\mathrm{z}}$ & $1330 \pm 50$ & $15 \pm 2$ & - \\
$P(k)$ & $1390 \pm 20$ & $14 \pm 2$ & $1.5 \pm 0.1$ \\
{$[\eta]$} & $1460 \pm 50$ & $14.5^{\mathrm{a}}$ & $2.3 \pm 0.2$ \\
\hline
\end{tabular}

\begin{tabular}{llll}
\hline \multicolumn{2}{l}{ ATPC in EA at $33{ }^{\circ} \mathrm{C}$} \\
Method & $M_{\mathrm{L}}\left(\mathrm{nm}^{-1}\right)$ & $\lambda^{-1}(\mathrm{~nm})$ & $d(\mathrm{~nm})$ \\
\hline$<S^{2}>_{\mathrm{z}}$ & $1250 \pm 50$ & $18 \pm 2$ & - \\
$P(k)$ & $1310 \pm 20$ & $16 \pm 2$ & $1.6 \pm 0.1$ \\
{$[\eta]$} & $1410 \pm 50$ & $17^{\mathrm{a}}$ & $2.3 \pm 0.2$ \\
\hline
\end{tabular}

\begin{tabular}{lllll}
\hline \multicolumn{2}{l}{ ATPC in MIBK at $25^{\circ} \mathrm{C}$} \\
Method & $M_{\mathrm{L}}\left(\mathrm{nm}^{-1}\right)$ & $\lambda^{-1}(\mathrm{~nm})$ & $d(\mathrm{~nm})$ & $B(\mathrm{~nm})$ \\
\hline$<S^{2}>_{\mathrm{z}}$ & $1190 \pm 50$ & $24 \pm 2$ & - & $0.5 \pm 0.5$ \\
$P(k)$ & $1230 \pm 40$ & $23 \pm 3$ & $1.7 \pm 0.1$ & - \\
{$[\eta]$} & $1310 \pm 50$ & $23.5^{\mathrm{a}}$ & $1.9 \pm 0.2$ & $0.5^{\mathrm{a}}$ \\
\hline
\end{tabular}

${ }^{a}$ Assumed. 


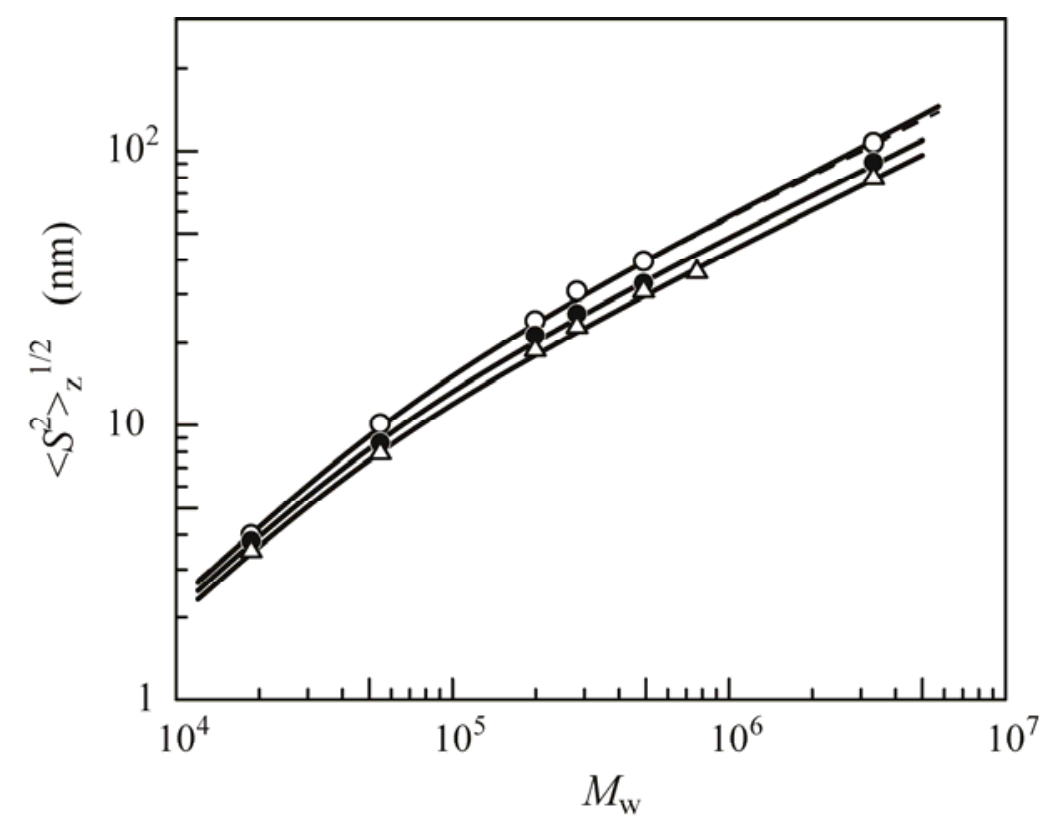

FIGURE 6 Comparison of the experimental $\left\langle S^{2}\right\rangle_{\mathrm{z}}$ for ATPC in MEA at $25^{\circ} \mathrm{C}$ (triangles), in EA at $33{ }^{\circ} \mathrm{C}$ (filled circles), and in MIBK at $25^{\circ} \mathrm{C}$ (unfilled circles) with the theoretical values calculated for the wormlike chains with the parameters in Table 2. For MIBK solutions, excluded-volume effects are corrected in the QTP scheme ${ }^{11,21,22}$ with the Domb-Barrett equation ${ }^{20}$ for the radius expansion factor. The dashed curve shows the unperturbed values for $B=0$.

\section{Particle Scattering Function}

Figure 7 shows that the Holtzer plots of $k P(k)$ vs $k$ for low-molar mass samples ATPC20K and ATPC50K in the three solvents have features typical of the wormlike chain with finite thickness. The solid curve fitted to the data points in each panel indeed represents Nakamura and Norisuye's theory ${ }^{23}$ for wormlike cylinders. In the curve fitting procedure, the $\lambda^{-1}$ values for ATPC $20 \mathrm{~K}$ in the three solvents were assumed to be the same as those for ATPC $50 \mathrm{~K}$ in the corresponding solvents. This is because for ATPC20K the dashed lines representing the rod-limiting values $\left(\lambda^{-1}=\infty\right)$ for the same $L$ and $d$ do not differ much from the solid curves for the wormlike chains with finite $\lambda^{-1}$, while those for ATPC50K differ from the solid curves for ATPC50K in the low- $k$ region, allowing unequivocal determination of $\lambda^{-1}$. 


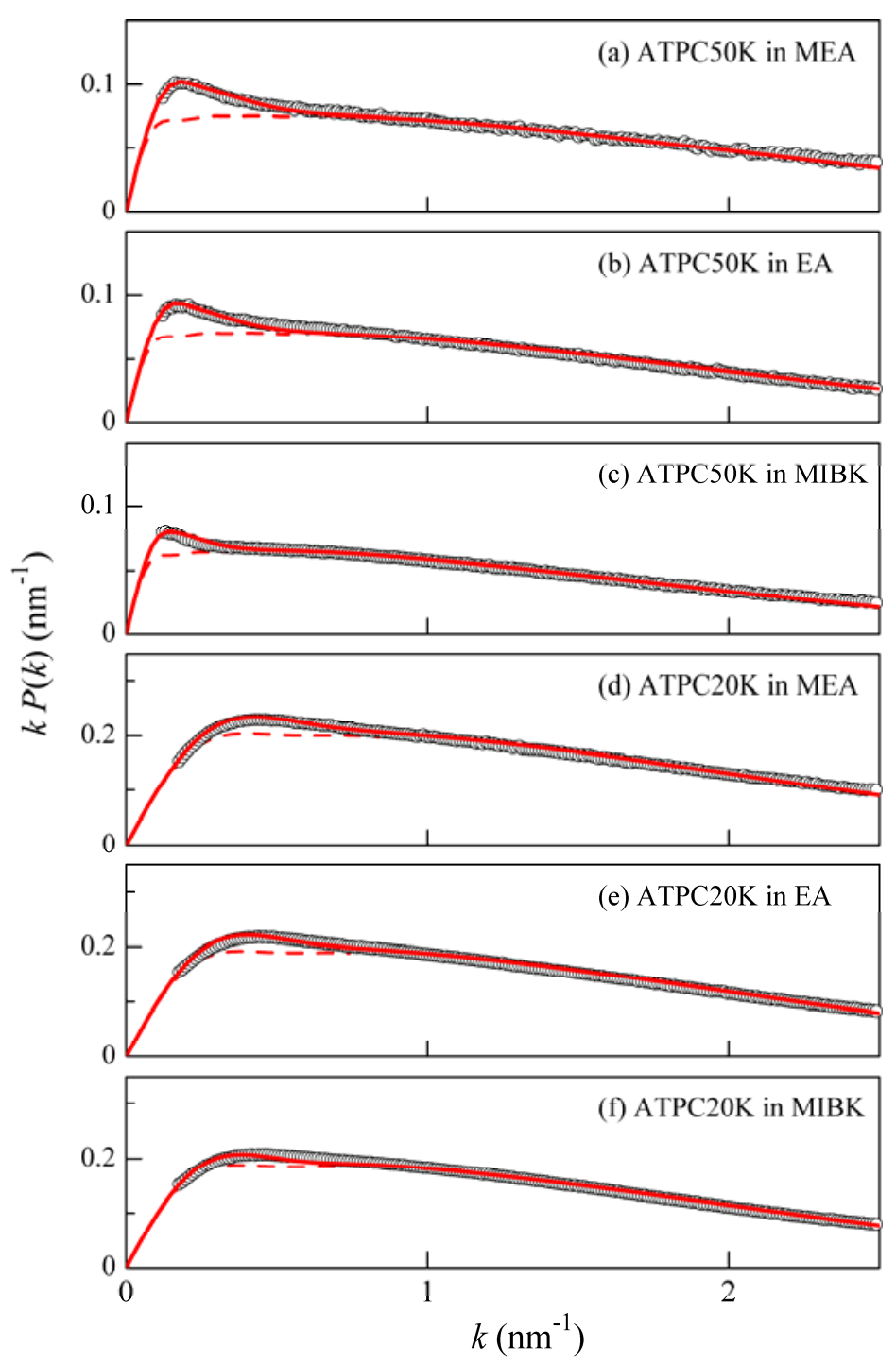

FIGURE 7 Holtzer plots for (a) ATPC50K in MEA at $25{ }^{\circ} \mathrm{C}$; (b) ATPC50K in EA at $33{ }^{\circ} \mathrm{C}$; (c) ATPC50K in MIBK at $25{ }^{\circ} \mathrm{C}$; (d) ATPC20K in MEA at $25{ }^{\circ} \mathrm{C}$; (e) ATPC20K in EA at $33{ }^{\circ} \mathrm{C}$; (f) ATPC20K in MIBK at $25{ }^{\circ} \mathrm{C}$. Solid curves, theoretical values for the unperturbed wormlike cylinders with the parameters listed in Table 2. Dashed curves, theoretical values in the rod limit $\left(\lambda^{-1}=\infty\right)$.

The values of $M_{\mathrm{L}}, \lambda^{-1}$, and $d$ (the chain diameter) thus estimated from $P(k)$ are summarized in Table 2, where for $M_{\mathrm{L}}$ and $d$, the averages for the two samples in each solvent are given because the difference in either parameter between the two samples is small. It can be seen that $M_{\mathrm{L}}$ and $\lambda^{-1}$ from $P(k)$ in the three solvents agree substantially with those from $\left\langle S^{2}>_{z}\right.$. Importantly, the mean $\left(1210 \mathrm{~nm}^{-1}\right)$ of the $M_{\mathrm{L}}$ values from these properties in MIBK is slightly smaller than those in the other two solvents and much smaller than the previously estimated value $1540 \mathrm{~nm}^{-1}$ in DIOX. This difference in $M_{\mathrm{L}}$ between MIBK and DIOX seems to be more than the uncertainty in our estimation and can indeed be seen directly from that in the height of $k P(k)$ (the so-called Holtzer plateau) around $k=0.5-1 \mathrm{~nm}^{-1}$ for ATPC50K (compare the scattering curve in panel (c) of Figure 7 
with that in panel (a) of Figure 8 in ref. 9). Another point to note here is that, when the $d$ values $(1.5-1.7 \mathrm{~nm})$ in the table are used, the contribution $\left(d^{2} / 8\right)$ from the chain thickness to $\left\langle S^{2}>_{0}\right.$ of the cylindrical wormlike chain ${ }^{24}$ is found to be about $2 \%$ and hence negligible.

\section{Intrinsic Viscosity}

The Yamakawa-Fujii-Yoshizaki theory ${ }^{11,25,26}$ for the intrinsic viscosity $[\eta]_{0}$ of an unperturbed wormlike cylinder contains $M_{\mathrm{L}}, \lambda^{-1}$, and $d$ as the parameters. Since all of these three cannot uniquely be determined from the present $[\eta]$ data, we used the mean of $\lambda^{-1}$ obtained from $\left\langle S^{2}>_{\mathrm{z}}\right.$ and $P(k)$ in each solvent. Excluded-volume effects in MIBK solutions were taken into account by use of the QTP theory with the Barrett equation ${ }^{27}$ for the viscosity expansion factor. The estimated parameters are presented in Table 2 and the theoretical $[\eta]$ values are shown by solid curves in Figure 8 , in which the dashed line represents the theoretical $[\eta]_{0}$ in MIBK. The excluded-volume effect is seen to be insignificant even for the highest $M_{\mathrm{w}}$ sample (less than $7 \%$ ) as is the case with $<S^{2}>_{\text {z }}$.

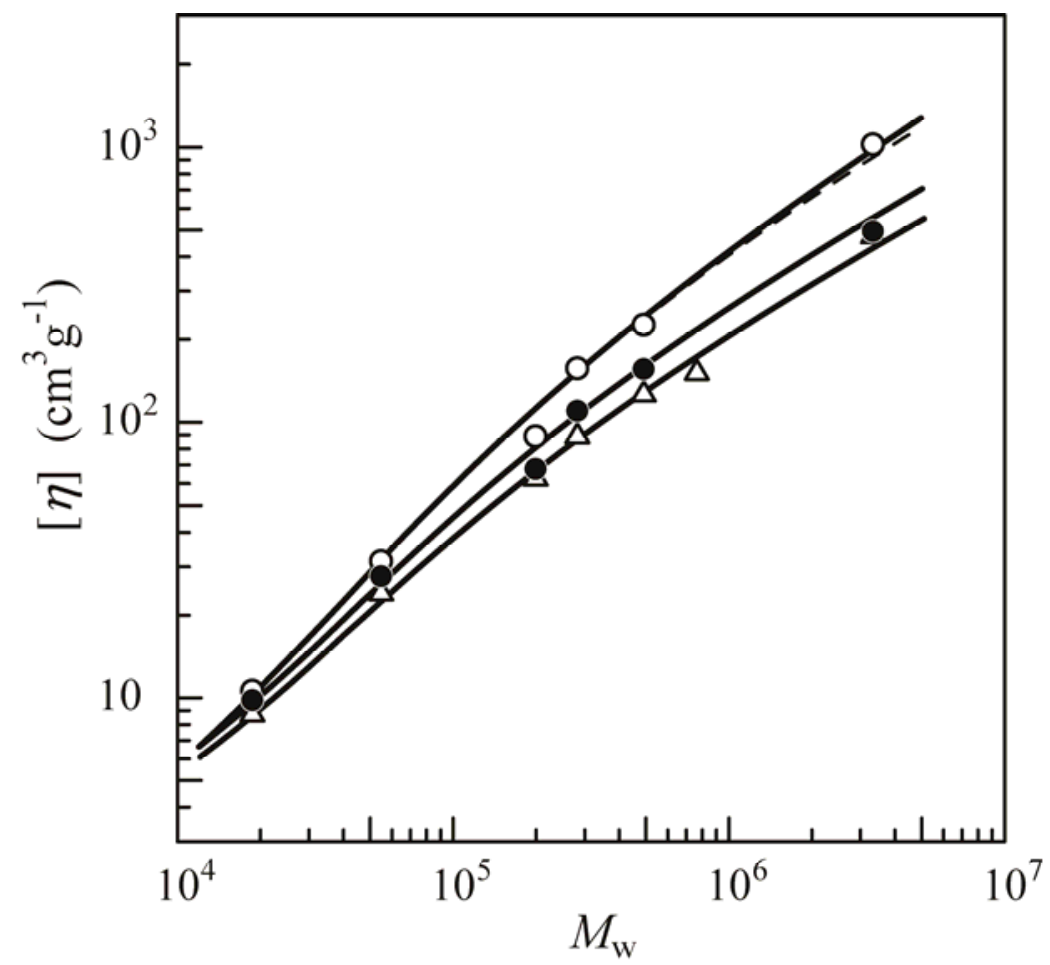

FIGURE 8 Comparison of the experimental $[\eta]$ for ATPC in MEA at $25^{\circ} \mathrm{C}$ (triangles), in EA at $33{ }^{\circ} \mathrm{C}$ (filled circles), and in MIBK at $25^{\circ} \mathrm{C}$ (unfilled circles) with the theoretical values calculated for the unperturbed wormlike cylinders ${ }^{11,25,26}$ and the Barrett equation ${ }^{27}$ for the viscosity expansion factor in the QTP scheme ${ }^{11,21,22}$ with the parameters in Table 2. The dashed curve shows the theoretical values for $B=0$.

The values of $M_{\mathrm{L}}$ and $\lambda^{-1}$ determined from $\left\langle S^{2}\right\rangle_{\mathrm{z}}, P(k)$, and [ $\left.\eta\right]$ in the respective solvents essentially agree with one another, leading to the conclusion that the available theories ${ }^{19,23,25,26}$ for 
the wormlike chain consistently explain the dilute-solution behavior of ATPC. It should be noted that the slightly smaller $M_{\mathrm{L}}$ values from $\left\langle S^{2}\right\rangle_{\mathrm{z}}$ than those from $P(k)$ and $[\eta]$ in the corresponding solvent are most likely due to the molecular weight distribution of our ATPC samples: The error is estimated to be at most $10 \%$ from the value of $M_{\mathrm{z}} / M_{\mathrm{W}}(\sim 1.1) .{ }^{9} \quad$ Although the $d$ values from $P(k)$ and $[\eta]$ do not always agree, the discrepancy may arise from the fact that $d$ from the former can be affected by the electron density profile around the chain contour. ${ }^{11,28,29}$ In the ensuing discussion, we use $d$ from $[\eta]$.

\section{Molecular Characteristics in Various Solvents}

Table 3 summarizes the means for $\lambda^{-1}$ and $h\left(=M_{0} / M_{\mathrm{L}}\right)$ and the $d$ values (from $[\eta]$ ) for ATPC in MEA, EA, and MIBK along with the previously determined values in DIOX and 2EE, where $M_{0}$ denotes the molar mass per repeating unit. Interestingly, $h$ varies with the kind of solvent and its difference between MIBK and 2EE amounts to 30\%. Furthermore, the values $(0.37-0.42 \mathrm{~nm})$ in MEA, EA, and MIBK are comparable to the helix pitches $(0.37-0.40 \mathrm{~nm})$ per residue of amylose triesters in the crystalline state. ${ }^{14,15}$ Thus, we may conclude that the shorter helix pitch of about $0.33 \mathrm{~nm}$ in DIOX or 2EE mentioned in the Introduction is not specific to ATPC in solution. In other words, the longer pitches or contour lengths per residue in the three polar solvents, the esters and the ketone, may be interpreted as the result of chain extension (along the helix axis) due to the breaking of intramolecular hydrogen bonds between the $\mathrm{C}=\mathrm{O}$ and $\mathrm{NH}$ groups of the polymer; according to our previous IR spectra, about $40 \%$ of the groups form hydrogen bonds in DIOX or $2 \mathrm{EE}$. It seems reasonable to consider that the $\mathrm{C}=\mathrm{O}$ groups of the solvent molecules break these hydrogen bonds and form intermolecular hydrogen bonds with $\mathrm{NH}$ groups of the polymer to compensate for the enthalpy loss. Moreover, the solubility of ATPC having LCSTs in all of the three solvents lends support to the presence of such intermolecular hydrogen bonds. On the basis of these considerations, we conjecture that each solvent molecule wedges itself into the domain sandwiched between the neighboring phenylcarbamate groups and that a molecule with a larger $v_{M}$ (MIBK $>$ EA $>$ MEA) occupies a larger domain to contribute toward extending the helix. This is consistent with the data in Table 3 showing that $h$ is a gradually increasing function of $v_{M}$ in the three solvents (see Figure 1 for the values of $v_{M}$ ).

The main-chain stiffness in the three solvents expressed in terms of $\lambda^{-1}$ also increases slightly with an increase in $v_{\mathrm{M}}$. We may explain this in a consistent way that the bulkiness of the solvent molecules interacting with the NH groups of ATPC through hydrogen bonding hinders the rotation of each virtual bond and thus stiffens the main chain. As was remarked previously, ${ }^{9}$ the ATPC chains in DIOX and 2EE are stiffened by the intramolecular hydrogen bonding between the $\mathrm{C}=\mathrm{O}$ and NH groups in addition to the bulky-substituent effect intrinsic to ATPC, but we are unable to discuss

further the $\lambda^{-1}$ data in Table 3 in relation to the solvent effect on chain stiffness. In short, the present analysis may be taken to show that, regardless of this effect, the helix pitch per residue gets 
longer by $10-30 \%$ when the intramolecular hydrogen bonds are replaced with the intermolecular ones by exchanging the solvent.

In Table $3, d$ tends to increase with decreasing $h$. This seems reasonable because a more tightly wound helix is generally thicker. However, the values of $d$ in MIBK, EA, and MEA may be regarded as roughly the same if the uncertainty indicated in Table 2 is taken into consideration. Thus it is only certain that the helices in these solvents are thinner than that with the shorter pitch of $0.33 \mathrm{~nm}$ in DIOX or 2EE. Since, irrespective of the magnitude of $v_{\mathrm{M}}$, the solvent molecules strongly interacting with the NH groups of ATPC are likely to be embedded in the domains surrounded by the neighboring phenylcarbamate groups, they may hardly contribute to the hydrodynamic diameter.

Table 3. Values of $h, \lambda^{-1}$, and $d$ for ATPC in Various Solvents

\begin{tabular}{ccccc}
\hline Solvent & $T\left({ }^{\circ} \mathrm{C}\right)$ & $h(\mathrm{~nm})$ & $\lambda^{-1}(\mathrm{~nm})$ & $d(\mathrm{~nm})^{\mathrm{b}}$ \\
\hline MIBK & 25 & $0.42 \pm 0.02$ & $24 \pm 2$ & 1.9 \\
EA & 33 & $0.39 \pm 0.02$ & $17 \pm 2$ & 2.3 \\
MEA & 25 & $0.37 \pm 0.02$ & $15 \pm 2$ & 2.3 \\
DIOX $^{\mathrm{a}}$ & 25 & $0.34 \pm 0.01$ & $22 \pm 2$ & 2.9 \\
2EE $^{\mathrm{a}}$ & 25 & $0.32 \pm 0.01$ & $16 \pm 2$ & 2.8 \\
\hline${ }^{\mathrm{a}}$ Ref 9. ${ }^{\mathrm{b}}$ From $[\eta]$. & & & &
\end{tabular}

\section{CONCLUSIONS}

Light and small-angle X-ray scattering and viscosity data for ATPC samples in MEA at $25^{\circ} \mathrm{C}$, in EA at $33{ }^{\circ} \mathrm{C}$, and in MIBK at $25^{\circ} \mathrm{C}$, all of which are capable of strongly interacting with the $\mathrm{NH}$ groups of the polymer, are presented and analyzed on the basis of the wormlike chain. The following conclusions may be drawn from the analysis.

1. MEA at $25^{\circ} \mathrm{C}$ and EA at $33{ }^{\circ} \mathrm{C}$ are theta solvents for the amylose derivative whose Kuhn segment lengths are as large as $15-24 \mathrm{~nm}$; the theta state has seldom been found for linear polymers with such high stiffness. ${ }^{30}$

2. The estimated $h$ values $(0.37-0.42 \mathrm{~nm})$ in MEA, EA, and MIBK are comparable to the helix pitches $(0.37-0.40 \mathrm{~nm})$ per residue of amylose triesters in the crystalline state, so that the previously found shorter helix pitch of about $0.33 \mathrm{~nm}$ in DIOX or 2EE is not specific to ATPC in solution.

3. Both $h$ and $\lambda^{-1}$ in the esters and the ketone slightly increase with increasing solvent molar volume, indicating that the bulkiness of the polar solvent molecules tends to extend the helix and to stiffen the main chain. 
We are grateful to Professor Takahiro Sato (Osaka University) for supplying a cellulose tris(phenylcarbamate) sample and fruitful discussions. The synchrotron radiation experiments were performed at the BL40B2 in SPring-8 with the approval of the Japan Synchrotron Radiation Research Institute (JASRI) (Proposal \#2007A1034, \#2007B1296, and \#2008A1313).

\section{REFERENCES}

1. Burchard, W. Z Physik Chem 1964, 42, 293-313.

2. Burchard, W. Makromol Chem 1965, 88, 11-28.

3. Banks, W.; Greenwood, C. T.; Sloss, J. Eur Polym J 1971, 7, 879-888.

4. Burchard, W. Br Polym J 1971, 3, 214-221.

5. Sutter, W.; Burchard W. Makromol Chem 1978, 8, 1961-1980.

6. Pfannemüller, B.; Schmidt, M.; Ziegast, G.; Matsuo, K. Macromolecules 1984, 17, 710-716.

7. Muroga, Y.; Hayashi, K.; Fukunaga, M.; Kato, T.; Shimizu, S.; Kurita, K. Biophys Chem 2006, 121, 96-104.

8. $\quad$ Bittiger, H.; Keilich, G. Biopolymers 1969, 7, 539-556.

9. Terao, K.; Fujii, T.; Tsuda, M.; Kitamura, S.; Norisuye, T. Polym J 2009, 41, 201-207.

10. Kratky, O.; Porod, G. Recl Trav Chim Pays-Bas 1949, 68, 1106-1122.

11. Yamakawa, H. Helical Wormlike Chains in Polymer Solutions; Springer: Berlin, 1997.

12. Nakanishi, Y.; Norisuye, T.; Teramoto, A.; Kitamura, S. Macromolecules 1993, 26, 4220-4225.

13. Norisuye, T. Polym J 1994, 26, 1303-1307.

14. Zugenmaier, P.; Steinmeier, H. Polymer 1986, 27, 1601-1608.

15. Takahashi, Y.; Nishikawa, S. Macromolecules 2003, 36, 8656-8661.

16. Kasabo, F.; Kanematsu, T.; Nakagawa, T.; Sato, T.; Teramoto, A. Macromolecules 2000, 33, 2748-2756.

17. Kitamura, S.; Yunokawa, H.; Mitsuie, S.; Kuge, T. Polym J 1982, 14, 93-99.

18. Berry, G. C. J Chem Phys 1966, 44, 4550-4564.

19. Benoit, H.; Doty, P. J Phys Chem 1953, 57, 958-963.

20. Domb, C.; Barrett, A. J. Polymer 1976, 17, 179-184.

21. Yamakawa, H.; Stockmayer, W. H. J Chem Phys 1972, 57, 2843-2854.

22. Shimada, J.; Yamakawa, H. J Chem Phys 1986, 85, 591-599.

23. Nakamura, Y.; Norisuye, T. J Polym Sci Part B: Polym Phys 2004, 42, 1398-1407.

24. Konishi, T.; Yoshizaki, T.; Saito, T.; Einaga, Y.; Yamakawa, H. Macromolecules 1990, 23, 290-297.

25. Yamakawa, H.; Fujii, M. Macromolecules 1974, 7, 128-135.

26. Yamakawa, H.; Yoshizaki, T. Macromolecules 1980, 13, 633-643.

27. Barrett, A. J. Macromolecules 1984, 17, 1566-1572.

28. Hickl, P.; Ballauff, M.; Scherf, U.; Mullen, K.; Lindner, P. Macromolecules 1997, 30, 273-279.

29. Terao, K.; Mizuno, K.; Murashima, M.; Kita, Y.; Hongo, C.; Okuyama, K.; Norisuye, T.; Bächinger, H. P. Macromolecules 2008, 41, 7203-7210.

30 Norisuye, T. Prog Polym Sci, 1993, 18, 543-584. 